D.O.I.: $10.3895 / \mathrm{S} 1808-04482011000100012$

\title{
UM ESTUDO SOBRE A APLICABILIDADE DO SISTEMA PUXADO DE PRODUÇÃO NA FABRICAÇÃO DE AÇUCAR
}

\section{A STUDY ON THE APPLICABILITY OF THE PULL PRODUCTION SYSTEM IN SUGAR MANUFACTURING}

\author{
Marcelo Giroto Rebelato ${ }^{1}$; Leonardo Lucas Madaleno ${ }^{2}$; Andréia Marize Rodrigues ${ }^{3}$; \\ ${ }^{1}$ Universidade Estadual Paulista Júlio de Mesquita Filho - UNESP - Jaboticabal - SP - Brasil \\ mgiroto@fcav.unesp.br \\ ${ }^{2}$ Centro Estadual de Educação Tecnológica Paula Souza - FATEC - Jaboticabal - SP - Brasil \\ leoagro@gmail.com \\ ${ }^{3}$ Universidade Estadual Paulista Júlio de Mesquita Filho - UNESP - Jaboticabal - SP - Brasil \\ andreiamarize@fcav.unesp.br
}

\section{Resumo}

O objetivo deste artigo é analisar a aplicabilidade do Sistema de Produção Puxada na fabricação do açúcar. Para isso, foram selecionados da literatura especializada que trata do tema Just-inTime, os requisitos básicos ao funcionamento do mecanismo de se "puxar a produção". Cada requisito selecionado foi confrontado com as características e particularidades do processo e da tecnologia atual de produção do açúcar. Concluímos que, apesar dos sucessos relatados na literatura com a aplicação do JIT em sistemas contínuos de produção, a produção puxada não se revela interessante ou factível à produção do açúcar.

Palavras-chave: sistema de produção puxada; fabricação do açúcar; sistema de produção puxada na fabricação do açúcar.

\section{Introdução}

O atual ambiente mercadológico global caracterizado por crescentes expectativas dos compradores, rápidas mudanças tecnológicas, mudanças nos padrões demográficos e de consumo e aumento da competição têm pressionado as empresas manufatureiras a buscar a redução de custos de fabricação, o incremento da qualidade, da flexibilidade na fabricação, da produtividade no chãode-fábrica, e a implantar uma ampla variedade de ferramentas, técnicas e filosofias gerencias inovadoras.

A adoção de inovações tecnológicas gerencias têm mostrado, em muitos casos registrados na literatura, ganhos operacionais e estratégicos relevantes às empresas que se empenham a enfrentar o desafio da implantação do Just-in-Time (JIT) (YASIN et al., 2001). O impacto positivo da adoção 
do JIT nos aspectos operacionais e estratégicos das empresas privadas é atualmente bem documentado (SHIN; MIN, 1991; WAFA; YASIN, 1998). Para Yasin et al. (2001), o JIT auxilia a eliminar os desperdícios na produção, incrementa a comunicação interna (dentro da organização) e externa (entre a empresa e seus consumidores e fornecedores), reduz custos de compras, de tempos de produção, incrementa a qualidade e a produtividade da organização.

O JIT utiliza o que é conhecido como "sistema puxado de produção". Neste sistema, a demanda gerada pelos consumidores é a geradora das ordens de fabricação. Quando o consumidor compra um produto do fabricante, uma unidade deste produto é retirada do estoque de produtos acabados do fabricante. Neste momento, um "sinal” é enviado à fabricação indicando que um novo produto deve ser fabricado para repor o produto que foi vendido. Dessa forma, o consumidor exerce o papel de "puxador" do sistema. Imaginando o sistema produtivo como uma sequência de tarefas (ou estágios de produção) em linha, a última tarefa (montagem final) ao ter um produto retirado, deve enviar um sinal de produção ao estágio anterior e assim sucessivamente, até que o primeiro estágio sinalize ao fornecedor de matérias-primas a necessidade de reposição do que foi retirado. $\mathrm{O}$ processo funciona com cada estágio produtivo "puxando" as partes necessárias do estágio anterior (MONDEN, 1998).

A vasta maioria de casos documentados na literatura especializada de aplicação da produção puxada é voltada à indústria de processamento discreto, não à indústria de processamento contínuo. De acordo com ABDULMALEK et al. (2006), no processamento discreto, a matéria-prima individualizada é movimentada de uma operação à outra de maneira que cada item singular é processado de forma individualizada em cada operação de agregação de valor. Processa-se, dessa forma, uma peça de cada vez. O processamento contínuo, por sua vez, pode ser entendido como um tipo de processamento com nenhuma ou quase nenhuma interrupção na linha seqüencial de operações de agregação de valor à matéria-prima, pois a matéria-prima, em geral, não pode ser dividida ou tomada de forma discreta, como uma "peça" individualizada. A indústria sucroalcooleira é um exemplo de indústria que emprega exclusivamente o processamento contínuo.

No entanto, os sistemas puxados são tão aplicáveis às indústrias de processamento contínuo quanto o são às indústrias de processamento discreto, podendo trazer igual benefícios a ambas (KING, 2009). Na planta da DuPont em Camden, estado da Carolina do Sul (EUA), onde produtos têxteis são fabricados, o JIT foi utilizado para resolver o problema de falta de produtos, estoques excessivos, e a falta ou a troca dos fios na área de fiação (BILLESBACH, 1994). Na Dow Chemical (EUA), os princípios do JIT foram usados entre a empresa e seus clientes para incrementar em $25 \%$ a acuracidade da previsão da demanda, para reduzir em $25 \%$ o lead-time médio de distribuição e para reduzir em 37\% os níveis de estoque em matérias-primas (COOK; ROGOWSKI, 1996).

Dado o exposto, o objetivo deste artigo é analisar a aplicabilidade da utilização do Sistema 
de Produção Puxada na fabricação de açúcar. O presente artigo contribui no aprofundamento da análise e no melhor entendimento sobre as possibilidades de incremento da eficiência e da eficácia das operações produtivas dentro da manufatura sucroalcooleira. Este debate é importante na medida em que o Brasil é nos dias de atuais, um pólo irradiador de tecnologia de produção de açúcar, além de ser o maior produtor de açúcar de cana do mundo, com os menores custos de produção, e também o maior exportador do produto com 20,8 milhões de toneladas exportadas na safra 2008/09, avaliadas em aproximadamente seis bilhões de dólares, segundo a Secretaria de Comércio Exterior (ADVFN, 2010).

\section{Metodologia de desenvolvimento}

A metodologia de pesquisa utilizada foi composta por quatro etapas, a saber:

1. Conceituação de sistemas puxados: o entendimento do sistema puxado com a utilização do cartão kanban é fundamental para a etapa seguinte;

2. Identificação dos requisitos básicos ao sistema puxado: a literatura especializada é farta em relação à implantação do JIT. JIT e sistemas puxados estão intimamente entrelaçados. No entanto, tratamos aqui da aplicabilidade do sistema puxado na indústria sucroalcooleira, não de todo o JIT. Dos requisitos preconizados à implantação do JIT, identificamos aqueles estritamente necessários à implantação do sistema puxado. Estes requisitos são apresentados e discutidos no item quatro. Os requisitos não estritamente necessários ao mecanismo de "puxar" a produção não foram incluídos. Partindo da definição que um sistema puxado é: "Um sistema que produz para repor o material que foi consumido, ou material para os quais existem pedidos firmes necessitando ser preenchidos imediatamente, e no qual o fluxo é controlado e estão sincronizadas com as condições atuais de operação" (KING, 2009, p.242), podemos inferir que as atividades e metodologias requeridas por um sistema JIT como (SALAHELDIN, 2005): (1) o gerenciamento da qualidade total (TQM), (2) a manutenção produtiva total (TPM), (3) a padronização das operações, (4) a integração cliente-fornecedor, (5) a redução do número de fornecedores, (6) a previsão da demanda, (7) os estudos para eliminação de todas as fontes de desperdício, (8) a conscientização e treinamento da mão-de-obra, são práticas complementares ao sistema puxado, ou seja, fazem parte da filosofia JIT, porém não têm impacto direto no mecanismo de "puxar" a produção e, portanto, não serão consideradas na análise em questão;

3. Descrição do processo de produção do açúcar e identificação das suas particularidades. $\mathrm{O}$ processo de produção do açúcar é complexo e extenso. Desse modo, ele foi descrito de forma simplificada, com detalhamento suficiente para possibilitar o entendimento da etapa seguinte;

4. Confrontação entre as etapas dois e três: analisamos a aplicabilidade de cada requisito do sistema puxado de produção identificado na etapa dois a partir do processo descrito na etapa três. 


\section{Sistemas puxados}

Conforme Corrêa e Corrêa (2004), o sistema JIT apresenta diferenças de abordagens com relação aos sistemas tradicionais empurrados. A principal é o mecanismo de "puxar" a produção ao longo do processo, de acordo com a demanda. No Sistema Puxado o material somente é processado em uma operação se ele é requerido pela operação subseqüente no processo, a qual, no momento necessário, envia um sinal que funciona como uma "ordem de produção" à operação fornecedora para que esta inicie a produção e a abasteça. Se um sinal não é enviado a operação não é iniciada.

Em contraponto aos sistemas puxados, os sistemas tradicionais "empurram" a produção desde a compra de matérias-primas e componentes até os estoques de produtos acabados. Uma vez completada a operação o lote é "empurrado" para a operação seguinte onde espera sua vez de encabeçar a fila de lotes a serem processados, de acordo com seu nível de prioridade.

A produção puxada é invariavelmente operacionalizada por meio do sistema kanban. Segundo Tubino (2000), nos sistemas convencionais de empurrar a produção, elabora-se periodicamente um programa de produção completo, da compra da matéria-prima à montagem do produto acabado, transmitindo por meio físico ou digital as ordens de compra, fabricação e montagem para cada um destes setores responsáveis. No sistema kanban de puxar a produção não se produz nada até que o cliente (interno ou externo) de seu processo solicite a produção de determinado item. Em outras palavras, afirma MONDEN (1984), o pessoal de certo processo vai ao processo precedente retirar as unidades necessárias na quantidade necessária e no tempo necessário. Assim, o processo precedente tem que produzir somente a quantidade suficiente de unidades para repor aquelas que foram retiradas. A quantidade e o tipo de unidades necessárias são descritos no kanban. O kanban é enviado para as pessoas de certo processo precedente por meio do processo subseqüente. Como resultado, muitos processos na fábrica são interligados uns aos outros. Esta interligação dos processos permite melhor controle das quantidades necessárias para vários produtos.

Em suma, o kanban (ou cartão kanban) é um sistema de informação idealizado para controlar harmoniosamente as quantidades de produção em todos os processos. São utilizados dois tipos principais de kanban: kanban de requisição e kanban de ordem de produção. Um kanban de requisição detalha a quantidade de que o processo subseqüente deve retirar, enquanto que um kanban de ordem de produção determina a quantidade que o processo precedente deve produzir. Para exemplificar, supor-se-á que a fábrica está produzindo produtos $\mathrm{A}, \mathrm{B}$ e $\mathrm{C}$ numa linha de montagem. As peças necessárias para produzir estes produtos são $\underline{\mathbf{a}}$ e $\underline{\mathbf{b}}$, as quais são produzidas pela linha de usinagem precedente (figura 1). As peças $\underline{\mathbf{a}}$ e $\underline{\mathbf{b}}$, produzidas pela linha de usinagem são estocadas atrás desta linha e os kanbans de ordem de produção da linha são afixados nestas peças. O 
abastecedor da linha de montagem que produz o produto A vai à linha de usinagem retirar as peças necessárias com um kanban de requisição. Então, no estoque, ele apanha algumas caixas destas peças com seus kanbans de requisição e destaca o kanban de ordem de produção afixado. Ele então traz estas caixas de volta para linha de montagem, novamente com os kanbans de requisição. Ao mesmo tempo, os kanbans de ordem de produção estão à esquerda do estoque da linha de usinagem, mostrando o número de unidades retiradas. Estes kanbans são as informações enviadas para alinha de usinagem. A peça a é então produzida na quantidade exata para aquele número de kanbans. Nesta linha de usinagem as peças $\underline{\mathbf{a}}$ e $\underline{\mathbf{b}}$, são produzidas de acordo com a ordem indicada pelos kanbans de ordem de produção (MONDEN, 1984).

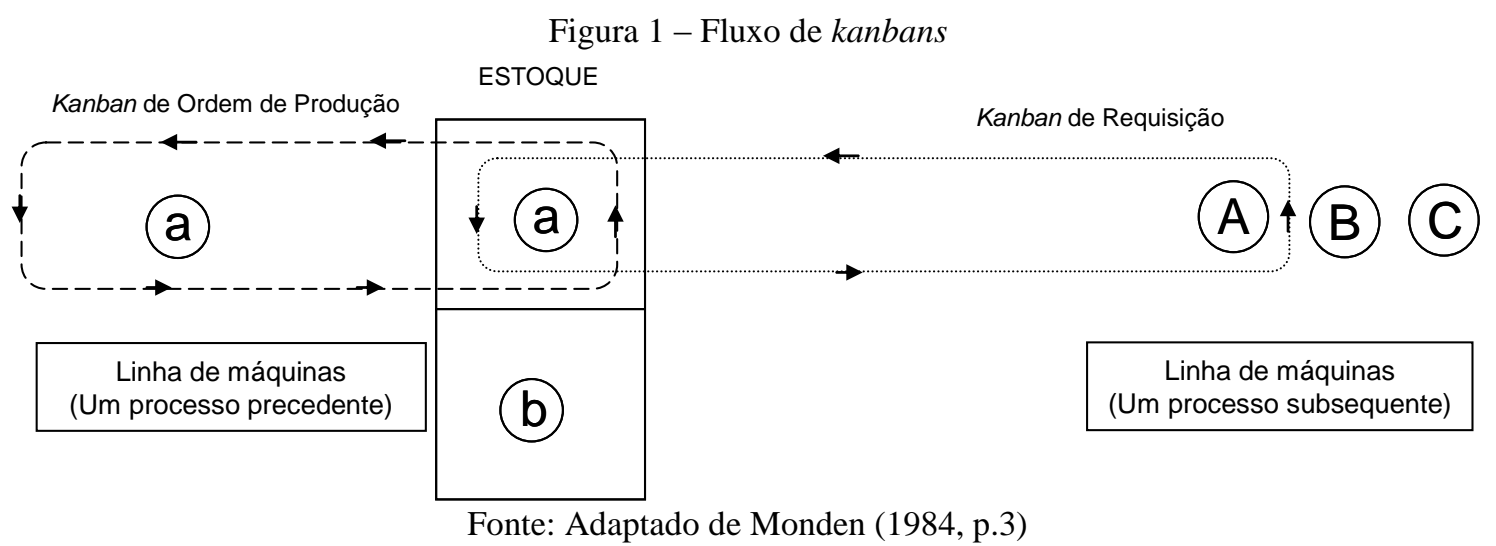

\section{Requisitos para um sistema de produção puxado}

Os requisitos abaixo foram selecionados a partir da sua atuação ou da sua utilidade em evitar-se a superprodução por meio da limitação explícita dos inventários até um nível mínimo necessário para assegurar um fluxo suave de produção e sincronizado ao ritmo de "puxada" do sistema pelo cliente de acordo com suas necessidades. Os requisitos selecionados para a análise do processo de produção do açúcar são abaixo relacionados:

a) Rápida parada e partida de máquinas. Dado que os sistemas puxados autorizam a produção exatamente na medida em que os produtos são demandados (HOPP; SPEARMAN, 2007), e que em qualquer tipo de indústria pode haver intensa flutuação no nível da demanda, os sistemas puxados requerem que as máquinas sejam paradas e reiniciadas em curto ou curtíssimo período de tempo;

b) Produção em pequenos lotes. Segundo Tubino e Andrade (2003), para os sistemas puxados é historicamente recomendado a adoção da produção de lotes repetitivos. Lotes pequenos e nivelados contribuem com a suavização do fluxo produtivo e para a diminuição dos estoques em processo;

c) Rápida troca de ferramentas (SMED - Single Minute Exchange of Die). Conforme Spearman e Zazanis (1992), os sistemas puxados requerem tempos de troca de ferramentas muitos 
curtos, pois as paradas das máquinas são consideradas tempos mortos que reduzem a produtividade do sistema;

d) Flexibilidade com máquinas pequenas e reorganização do layout. Para Mould e King (1995), a implantação da produção puxada requer uma preparação da fábrica para o incremento do fluxo produtivo com flexibilidade de máquinas. As máquinas com menores dimensões são mais fáceis de manusear, a manutenção é mais simples e rápida, além de possibilitarem maior flexibilidade na reorganização do layout produtivo. Dessa forma, as máquinas menores se adéquam à produção de lotes menores e auxiliam na obtenção de dois objetivos do JIT: flexibilidade e economia;

e) Combinação de operações em células produtivas. Combinar as operações produtivas em células é possível quando se tem uma família de produtos a processar, ou seja, alguns produtos, tendo todos eles características comuns, o que implica na utilização das mesmas máquinas para produzi-los e com ajustes similares para os equipamentos. Dessa forma, as mudanças de máquinas são simplificadas, os produtos podem ser feitos e embarcados mais rapidamente e os custos de manuseio são reduzidos (GAITHER; FRAZIER, 2001);

f) Reduzir o tempo de atravessamento (shorten the lead-time). Para Tubino (1999), o tempo de atravessamento é o tempo gasto pelo sistema para transformar a matéria-prima em produto acabado, estando nele incluídos os tempos de espera, processamento, inspeção e transporte. A redução do lead-time por um lado é positiva, pois requer redução dos estoques em processo (SHINGO, 1996) e, por outro lado, reduz o tempo necessário entre pagar pela matéria-prima e receber pelo produto acabado, ou seja, um lead-time menor significa maior giro de estoques (ROTHER; SHOOK, 2003). Adicionalmente, trabalhar com lead-times reduzidos implica em responder rapidamente às mudanças de pedidos quando se fabrica uma grande variedade de produtos (CORRÊA; CORRÊA, 2004);

g) Fornecimento Just-in-time. Segundo Swanson e Lankford (1998), num sistema puxado, as matérias-primas são compradas e recebidas em pequenas quantidades somente no momento em que são necessários para a produção. Dessa forma, os sistemas puxados são sistemas que devem se estender ao material recebido pelos fornecedores. Isto significa que os fornecedores devem se adequar às necessidades dos compradores, fornecendo os insumos apenas momento em que estes sejam demandados (MOURA, 2000), o que implica que o fornecedor deve armazenar os insumos até a data de entrega ao fabricante. Como corolário desta assertiva, as matérias-primas devem ser estocáveis.

\section{O processo de produção do açúcar}

O processo de produção de açúcar (Figura 2) é aqui descrito de forma simplificada, 
contemplando um nível de detalhamento apenas suficiente para a análise pretendida. O processo descrito tem início a partir da etapa de recepção da cana na usina de açúcar, que é a primeira etapa industrial. As etapas de campo, anteriores às etapas industriais, que envolvem a produção da matéria-prima como plantio, colheita e transporte não serão consideradas neste estudo. Como fontes bibliográficas para o processo de produção de açúcar têm-se: Marafante (1993), Copersucar (2010), Hamerski (2009), Magalhães (2010a, 2010b, 2010c, 2010d, 2010e, 2010f), Paulino (2010) e Pelegrini (2009).

A primeira etapa para a produção do açúcar é a recepção da cana, que é mecanizada, utilizando tombador hidráulico para basculamento lateral dos caminhões, hillo, ou ponte rolante, que deposita a carga de cana diretamente na mesa alimentadora da esteira principal, que conduz a mesma à etapa de preparo para a posterior moagem. A cana picada pode ser descarregada diretamente nas esteiras. A cana inteira, por ouro lado, deve ser descarregada em mesas laterais para o processo de lavagem, com a função de retirar impurezas minerais.

A próxima etapa, o preparo da cana, tem como objetivo reduzir a resistência da parte dura da cana (nós e cascas), facilitando a moagem e permitindo romper a estrutura dos vasos celulares da medula (que contém a maior parte do caldo), aumentando a taxa de extração para a etapa seguinte, a extração do caldo. O preparo consiste em picar e desintegrar a cana, rompendo as células que contêm o caldo rico em açúcares.

Depois do preparo da cana temos a extração do caldo (ou “moagem"), geralmente executado por processo de esmagamento da cana-de-açúcar efetuado por meio de moendas ou por difusão. Durante a passagem da cana pelas moendas surgem naturalmente impurezas na forma de pequenos fragmentos do bagaço que são denominados "bagacinho".

Dessa forma, torna-se necessário o processo de peneiragem do caldo para a remoção das impurezas físicas. Isto se faz necessário antes que se passe a fase de clarificação, pois as impurezas podem provocar entupimentos de bombas, propiciando incrustações em canalizações, e em tubulações dos corpos aquecedores e evaporadores, prejudicando também a qualidade do produto final.

A próxima etapa é a de sulfitação do caldo (considerando-se que o processo está direcionado à produção do açúcar cristal branco) que consiste em promover o contato do caldo com o gás sulforoso $\left(\mathrm{SO}_{2}\right)$ para sua absorção. A sulfitação do caldo implica em redução do seu $\mathrm{pH}$ de valores entre 5 a 5,50 para 3,8 a 4,3. A principal reação química, entretanto, ocorre com o hidróxido de cálcio usado na caleagem na etapa seguinte, produzindo o precipitado sulfito de cálcio que, ao ser eliminado na decantação, arrasta impurezas e permite a obtenção de um caldo límpido e claro.

$\mathrm{O}$ pH do caldo atinge então a faixa de 7,2 a 7,8. Portanto, a caleagem aumenta o pH do caldo, garantindo a presença de íons $\mathrm{Ca}^{2+}$ que irão precipitar-se juntamente com o sulfito existente 
no caldo. Além da formação de compostos insolúveis, ocorre a coagulação de grande quantidade de colóides pela ação do aumento de temperatura no processo de aquecimento antes da etapa de decantação.

Para o processo de produção do açúcar bruto do tipo VHP (Very High Polarization) é utilizado somente o processo de caleagem e o $\mathrm{Ca}^{2+}$ presente no caldo reage com o fosfato, formando um complexo insolúvel.

O caldo, para ambos os processos, é aquecido por vapor em trocadores de calor até a temperatura de 100 a $105^{\circ} \mathrm{C}$. $\mathrm{O}$ aquecimento do caldo acelera as reações químicas que levam à formação de compostos insolúveis, possibilitando a coagulação das proteínas e a floculação dos colóides do caldo, reduzindo a solubilidade dos sais de cálcio e a viscosidade do meio, acelerando a decantação e consequentemente à clarificação do caldo. Além disso, o aumento da temperatura auxilia no controle microbiológico e diminui a densidade e viscosidade do caldo.

Após o aquecimento o caldo vai para o balão flash (processo de "flasheamento"), que tem a função de liberar todas as partículas em suspensão nas bolhas de ar que ali estão agregadas e que comprometeriam a decantação e clarificação se não fossem retiradas. O flasheamento consiste na expansão brusca do caldo de modo que partindo da pressão presente na tubulação, o caldo atinja a pressão atmosférica. Esta ebulição explosiva e violenta elimina o ar e os gases dissolvidos contidos no caldo, inclusive aquele adsorvido na superfície das partículas de bagacilho.

A sedimentação ou decantação é um processo destinado à purificação do caldo por meio da remoção das impurezas floculadas. Este processo é realizado de forma contínua em equipamento denominado clarificador ou decantador, que possui vários compartimentos (bandejas), com a finalidade de aumentar a superfície de decantação. Existe outro tipo de decantador, sem bandeijas, que acelera o processo e vem sendo utilizado pelas usinas. Para ambos, os objetivos da decantação são a precipitação e a coagulação tão completa quanto possível dos colóides, obtenção do máximo volume de borras (com borras densas) e tornar o caldo o mais claro possível.

O processo de decantação produz por um lado, o caldo clarificado (que será enviado para o processo de pré-evaporação) e por outro lado, o lodo ou borra (composto pelas impurezas floculadas) que é retirado por baixo nos decantadores. Para o resíduo da decantação é utilizado o processo de filtração, que pode ser realizado por dois equipamentos, o filtro rotativo e/ou o filtro prensa. O processo de filtração atua sobre o lodo de forma a recuperar o açúcar nele contido retornando-o ao processo produtivo na forma de caldo filtrado. Isto porque o lodo removido dos decantadores possui uma considerável quantidade de açúcar e, portanto, deve ser aproveitado. Após sair do decantador o lodo recebe pequena quantidade de polímero, que ajudará na separação das impurezas, e recebe também adição de bagacilho, que aumentará o rendimento dessa extração. $\mathrm{O}$ material retido nos filtros recebe o nome de torta e pode ser enviado à compostagem e, a seguir, à 
lavoura para ser utilizado como adubo.

O caldo clarificado é filtrado após a decantação e é enviado ao pré-aquecedor (etapa de préevaporação). O processo de pré-evaporação tem a finalidade de elevar o Brix do caldo clarificado de 16 a 18 para ao redor de $25^{\circ}$ Brix e gerar vapor vegetal a partir da água existente no caldo.

A próxima etapa, evaporação, promove a concentração final desejada no caldo. O caldo préevaporado é enviado ao processo de evaporação para eliminar o excesso de água, transformando o caldo em xarope com cerca de $65^{\circ}$ Brix, no qual ainda não existem cristais de açúcar. A quantidade de água removida na evaporação é cerca de $80 \%$ da massa do caldo ou aproximadamente $70-80 \%$ da massa da cana.

O xarope que é proveniente dos evaporadores segue para os tanques de xarope, que são tanques de espera (tanques pulmão). Dessa forma, na próxima etapa, a de cozimento, o cozedor é alimentado pelo tanque de xarope. Coloca-se no cozedor certa quantidade de xarope, que é concentrada até a supersaturação do xarope e aparecimento de cristais de sacarose. Continua-se a alimentação da massa supersaturada com xarope. Os cristais vão crescendo e o volume total aumentando. No final, tem-se uma massa muito densa denominada "massa cozida", rica em cristais de sacarose. Essa massa será descarregada nos cristalizadores (próxima etapa) de modo a resfriar-se e completar o processo de cristalização da sacarose. A concentração desta massa cozida é de aproximadamente $93^{\circ}-95^{\circ}$ Brix, e a temperatura, ao ser descarregada, é de $65^{\circ}-75^{\circ} \mathrm{C}$. Dependendo das conveniências pode-se trabalhar com os sistemas de uma, duas ou três massas cozidas. Geralmente, nas usinas, é utilizado o processo de duas massas. O objetivo consiste em aumentar a esgotabilidade da sacarose do mel e aumentar o rendimento na produção de açúcar. Entretanto, este processo não é capaz de esgotar toda a sacarose. Como resultado dessa limitação do processo de cristalização tem-se a produção residual do chamado "melaço" (ou mel final) que será convenientemente direcionado a fabricação de etanol (Figura 3).

Partindo dos cristalizadores, a massa cozida resfriada segue para o processo de centrifugação. A centrifugação consiste na separação do mel que envolve os cristais de açúcar pela utilização da força centrífuga. Para a centrifugação é utilizado dois tipos de equipamentos: a centrífuga intermitente (ou “em batelada') e a contínua. A centrífuga intermitente é responsável pela centrifugação da massa A, ou seja, pela separação do açúcar (que seguirá para os processos de secagem e classificação) do mel final. Dessa forma, saem das centrífugas por um lado, o açúcar e do outro, o mel. Há a produção de dois tipos de mel a partir da massa A. O mel pobre, que é o primeiro a ser retirado do processo de centrifugação (e que será levado ao cozedor B para ser esgotado), e o mel rico, resultado do processo de lavagem do açúcar com água e vapor (que pode ser levado ao cozedor A ou ao B).

À medida que se esgota a sacarose do mel há o incremento da sua viscosidade, dificultando 
a purgação pela centrifuga intermitente. Para as massas mais viscosas, massas B ou C, é utilizado a centrifugação contínua, que possuiu força maior na separação. Porém, nesse caso existe a quebra de cristais que não podem ser utilizados para a comercialização. O açúcar quebrado é misturado com xarope ou caldo clarificado formando o magma que será utilizado como pé de cozimento no cozedor A.

Depois de centrifugado, o açúcar deve ser secado. A operação de secagem do açúcar consiste basicamente na redução da umidade e pelo resfriamento simultâneo a níveis que permitam a armazenagem por períodos relativamente longos sem que ocorram alterações significativas de suas características, isto é, preservando sua qualidade para consumo como produto alimentício.

Do secador, o açúcar é recolhido a uma moega com fundo afunilado que o despeja diretamente no saco localizado sobre uma balança, realizando, portanto, a operação de ensaque e pesagem. Máquinas de costura industriais realizam o fechamento do saco, que está pronto para a armazenagem. O açúcar é armazenado geralmente em sacos de $50 \mathrm{~kg}$, forma utilizada para o açúcar do tipo cristal e em armazéns sem janelas, com pouca ventilação e impermeáveis à água. O açúcar pode ser armazenado também a granel, no formato de pirâmide. Essa forma de armazenamento é a preferida para o açúcar do tipo VHP. 
Figura 2 - O processo de produção do açúcar




Figura 3 - Processo de produção de duas massas de açúcar

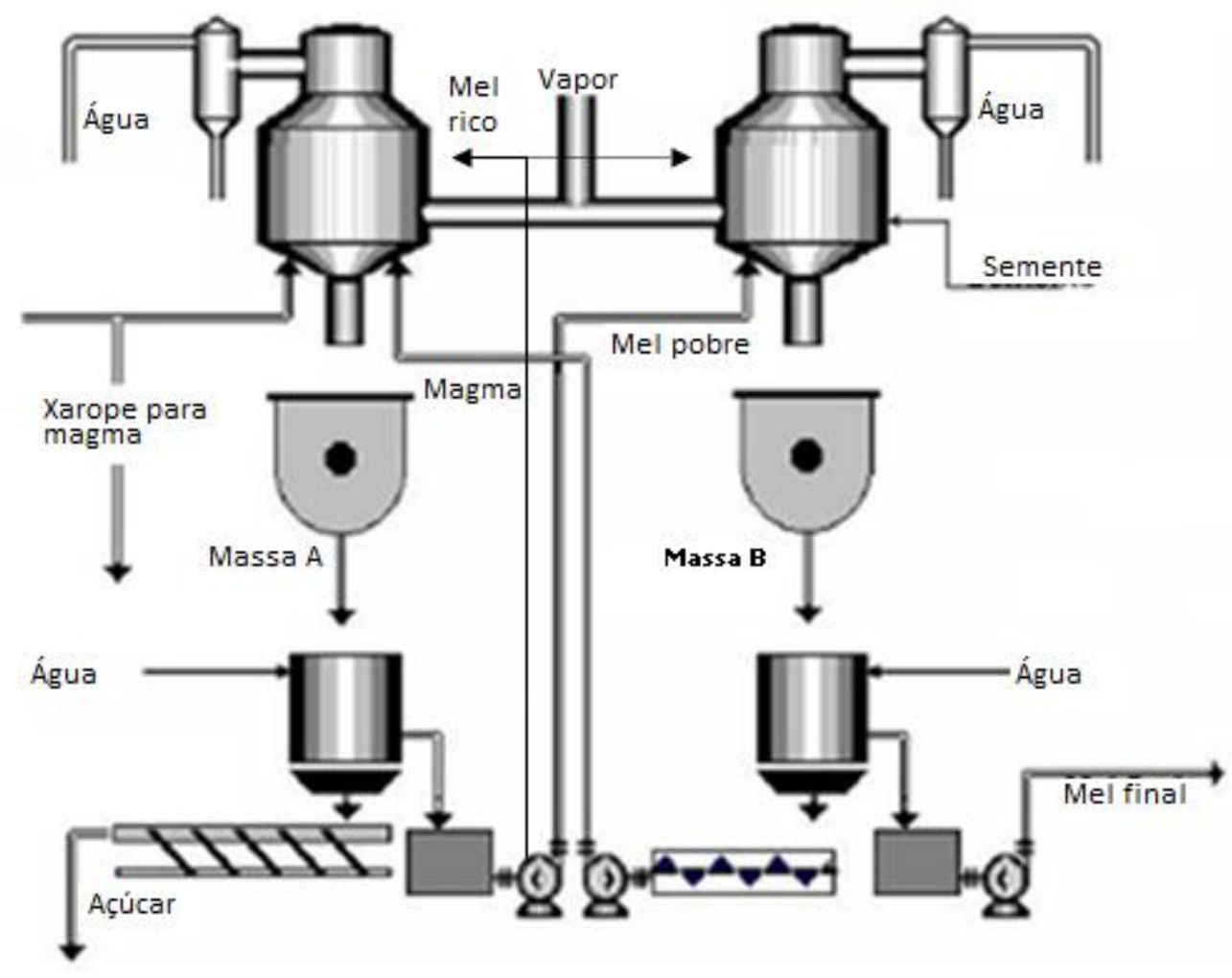

Fonte: Adaptado de Magalhães (2010)

\section{Análise da aplicabilidade do sistema puxado de produção na fabricação do açúcar}

Os dois principais produtos das usinas sucroalcooleiras brasileiras - o açúcar e o etanol disputam a mesma matéria-prima e é impossível separar-se o processo de fabricação do açúcar do processo de produção do etanol. Desse modo, um determinado mix de produção entre estes dois produtos é estabelecido pelos produtores todos os anos com base no retorno financeiro. Nos anos de maior demanda do mercado (interno e externo) pelo açúcar as usinas direcionam a matéria-prima para o processo de síntese de cristais. No momento em que as condições de mercado são ruíns para o açúcar, como por exemplo, quando há queda de preço por superprodução em âmbito internacional, há o direcionamento das canas colhidas para a produção de etanol.

Conforme apontado no item dois, cada requisito identificado para um sistema puxado de produção é analisado abaixo sob a luz das particularidades do processo de produção do açúcar:

a) Rápida parada e partida de máquinas. As paradas no processo de produção do açúcar ocorrem de forma programada, como para a limpeza e manutenção das máquinas, equipamentos e dispositivos no final do período de colheita da cana. Paradas não programadas também podem ocorrer quando, por exemplo, fatores adversos como as chuvas, que prejudicam a colheita da matéria-prima, impedem a sequência de produção. Como acontece nas indústrias de processos contínuos em geral, a indústria sucroalcooleira trabalha com equipamentos dedicados e de grande 
porte. São equipamentos que não podem ser desligados e religados em curtos ou curtíssimos períodos de tempo;

b) Produção em pequenos lotes. Pode-se pensar que os lotes pequenos de produção, além de contribuírem para a diminuição dos estoques em processo permitem a fabricação de uma maior variedade de produtos. Este claramente não é o caso da fabricação do açúcar que, por um lado, possui processo contínuo de fabricação sem estoques intermediários, e por outro lado, possui baixo nível de diferenciação. Da extração à evaporação do caldo, o processo é contínuo. O xarope é um subproduto que poderia ser armazenado por maior período de tempo com riscos mínimos de deterioração microbiológica para ser utilizado na medida em que o consumidor adquirisse o açúcar. Entretanto, esse subproduto é utilizado de forma sistêmica no processo de cozimento para a produção de cristais, de maneira que o seu estoque ocorre em pequena quantidade. $O$ armazenamento do xarope ocorre somente para não interromper o processo de produção posterior. Ainda, o xarope pode ser direcionado à produção de etanol. Não depende, entretanto, do consumidor final se o xarope será ou não utilizado para a produção de açúcar;

c) Rápida troca de ferramentas. A produção de diferentes tipos de açúcar, cristal ou VHP, não exige trocas de ferramentas na linha de produção e os equipamentos utilizados são basicamente os mesmos, com excessão ao processo de sulfitação realizado em colunas para o açúcar tipo cristal branco. Desse modo, não faz sentido em pensar agilizar as trocas de ferramentas na produção de açúcar. Por outro lado, existem unidades produtoras que possuem diferenciação na produção de açúcar, como o açúcar líquido e líquido invertido que requerem diferentes tipos de equipamentos e assim pode-se pensar em agilizar o set-up dependendo do tipo de produto em fabricação. Entretanto, plantas direcionadas aos acúcares líquidos são excessões na indúsdria sucroalcooleira nacional;

d) Flexibilidade com máquinas pequenas e reorganização do layout. A utilização de máquinas e equipamentos de pequeno porte na produção de açúcar significaria o comprometimento de um princípio fundamental para a indústria: a economia de escala. A indústria do açúcar necessita da operação em grande escala durante o período de safra da cana (de abril a novembro) exigindo, desse modo, máquinas e equipamentos de vulto. Por outro lado, o layout da fábrica de açúcar é preparado para a fabricação contínua. Até o processo de cozimento, o líquido açucarado circula pela planta industrial por meio de bombeamento. Na etapa de cozimento existe o planejamento para aproveitar a gravidade para a economia de energia no sistema. Os cozedores são colocados acima dos cristalizadores, que por sua vez estão acima das centrífugas e abaixo destas está a esteira que conduz o açúcar para o processo de secagem. O mel é bombeado retornando aos cozedores para recuperar o máximo de sacarose contido. Dessa forma, a reorganização do layout produtivo na fabricação do açúcar não é uma tarefa rápida ou trivial; 
d) Combinação de operações em células produtivas. Como já citado, o processo de produção de açúcar é do tipo dedicado. Neste contexto, não faz sentido pensar em combinarem-se as operações em células produtivas, pois a estrutura dos processos faz com que somente seja possível produzir um tipo de açúcar de cada vez;

e) Reduzir o tempo de atravessamento. O tempo de entrada da matéria-prima na indústria até sua transformação em produto final gira em torno de 8 a 10h. Há vinte anos o lead-time era substancialmente maior, entre 60 a 100\%. Porém, com as inovações tecnológicas e a automação do sistema produtivo, houve redução do tempo requerido para a mudança da matéria-prima em produto final. No sistema produtivo não há estoque em processo. O açúcar é o produto final que é acumulado nos armazéns à espera de comercialização. Os açúcares do tipo VHP ou cristal ficam armazenados na usina, que espera o momento de melhor preço do mercado para sua comercialização. Algumas unidades trabalham com o mercado futuro e possuem compromisso de fabricar os cristais para atender aos pedidos em carteira. Nessas, há necessidade de planejamento da colheita da cana para o processamento programado de modo que consigam honrar os contratos, respeitando sempre o período mínimo de maturidade da cana-de-açúcar. Entretanto, uma redução do lead-time é sempre possível, e uma estratégia para isso é atacar todos os gargalos do sistema produtivo. Conforme Brennan (2004), a distribuição da capacidade em uma fábrica resulta de tentativas de acomodar incertezas de projeto e dificuldades construtivas do processo. Desse modo, a redução do lead-time se situa na identificação e exploração das capacidades marginais nas várias etapas do processo. Esta estratégia é conhecida como “debottlenecking” (“desgargalamento"). Para a distribuição do processo fictício exibido pela Figura 4 abaixo, por exemplo, um incremento de $20 \%$ em toda a planta é alcançável simplesmente pela incremento de $20 \%$ na epata 1.

Figura 4 - Possibilidade de distribuição de capacidade numa planta de fabricação de açucar

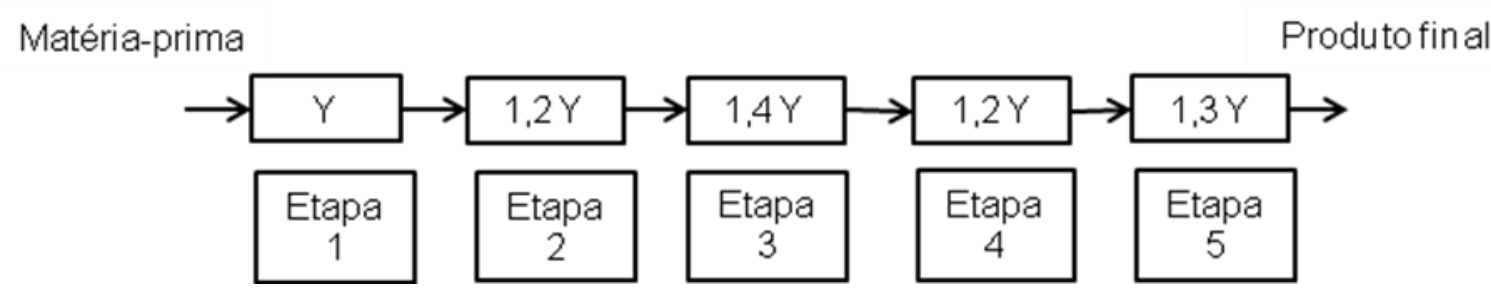

Fonte: Adptado de Brennan (2004, p.237)

Por outro lado, conforme Eid et al. (1998), a automação da indústria sucroalcooleira possibilita aumentar a velocidade de processamento das informações dentro da fábrica, pois as operações produtivas tendem a ser cada vez mais complexas e variáveis, necessitando de um grande número de controles e mecanismos de regulação para permitir decisões mais ágeis e, portanto, aumentar os níveis de produtividade e eficiência do processo produtivo. A automação permite economias de energia, força de trabalho e materiais, um melhor controle de qualidade do produto, 
aumenta a produtividade dos empregados e pode reduzir problemas de segurança. A automação nas indústrias sucroalcooleiras, a exemplo das indústrias de processo contínuo, permite incrementar a continuidade global do processo. Aumentar a produtividade significa maximizar a relação produção real/capacidade nominal das máquinas e equipamentos. Adicionalmente, contribui na redução das horas de parada por necessidades de preparação, manutenção corretiva dos equipamentos e falta de matéria-prima para abastecer o processo produtivo;

f) Fornecimento Just-in-time. A colheita da matéria-prima é definida pela safra e não pelos pedidos do consumidor. A cana-de-açúcar somente pode ser colhida depois de passado o tempo necessário para acúmulo de sacarose nos colmos. A época do ano para o corte da cana é bem definida, a colheita ocorre entre abril e novembro quando as chuvas são mais escassas e a temperatura média do ambiente é mais amena. O período de entressafra é utilizado para a realização de reparos nas máquinas e melhoria do processo produtivo. Esse fator limita muito o fornecimento Just-in-Time.

\section{Conclusões}

A partir da possibilidade vislumbrada pela literatura especializada internacional sobre a possibilidade da utilização da produção puxada em sistemas de fabricação contínuos, este artigo realizou uma análise sistemática sobre a factuabilidade da produção puxada na fabricação do açúcar. Dos seis requisitos analisados como indispensáveis à implantação da produção puxada, apenas um deles foi considerado factível.

Depreende-se que na usina de açúcar a rápida parada e partida das máquinas, essencial à produção puxada, não é tarefa simples e nem mesmo desejada pela função produção da empresa. Simplesmente não é possível realizar esta tarefa em curto ou curtíssimo período de tempo.

Por outro lado, a fabricação de pequenos lotes, importante à lógica de funcionamento do sistema puxado, não se mostra realizável na fabricação do açúcar, pois o processo é do tipo contínuo com possibilidades muito restritas de diferenciação do produto final dadas as características da tecnologia em uso.

A troca rápida de ferramentas, que permite à produção puxada a realização da chamada "virada de linha" - termo utilizado no jargão industrial para a mudança da linha de produção - não faz sentido em um ambiente de baixa diferenciação como o da produção do açúcar. Dessa forma, a troca de ferramental não se faz necessária, e nem mesmo as plantas de produção do açúcar estão preparadas para uma larga diferenciação do produto final.

Por outro ponto de vista, a flexibilidade requerida pelo sistema puxado de produção não é possível na fábrica do açúcar. O arranjo físico é planejado para fabricação contínua em grandes volumes. Dessa forma, e a economia de escala que viabiliza financeiramente o negócio exige 
equipamentos de grande porte de difícil movimentação.

A combinação das operações em células produtivas, um mecanismo do sistema puxado com vistas à redução dos estoques em processo e agilização da fabricação é uma idéia que não faz sentido já que somente é possível produzir-se um tipo de açúcar de cada vez. Além disso, células produtivas se viabilizam quando, a partir de uma job-shop circunjacente, a empresa desloca equipamentos para a fabricação de uma família de peças - peças com características físicas similares - que tenham pedidos em um regime de demanda estável e num nível que justifique economicamente esta mudança.

Entretanto, a redução do lead-time é perfeitamente possível na fabricação do açúcar. Temos visto que, com o passar dos anos, a automação e o avanço tecnológico dos equipamentos proporcionou substancias reduções no tempo de atravessamento dentro da fábrica. A redução do lead-time é de interesse para a indústria do açúcar na medida em que significa um aumento na produtividade da sua manufatura. Essa redução, contudo, não contempla o objetivo subjacente ao sistema puxado de produção especificamente com a redução do tempo de atravessamento que é responder rapidamente às mudanças de pedidos quando se fabrica uma grande variedade de produtos.

De todos os fatores analisados, o que mais intensamente se contrapõe à possibilidade da introdução da produção puxada na fabricação do açúcar parece ser a impossibilidade de armazenamento da matéria-prima. A cana-de-açúcar depois de colhida no campo se degrada facilmente, o que faz com que o extremo do sistema produtivo oposto ao cliente, o extremo onde se localiza o fornecimento da matéria-prima, se transforme numa barreira intransponível à introdução da fabricação no ritmo da "puxada do cliente", considerando-se a tecnologia atualmente disponível.

Dessa forma, concluímos que, apesar dos sucessos relatados na literatura com a aplicação do JIT em sistemas contínuos de produção, a produção puxada não se revela interessante ou factível à produção do açúcar.

\begin{abstract}
The objective of this paper is to analyze the applicability of the Pull Production System in sugar manufacturing. For that, were selected from the specialized literature that treats the subject Just-in-Time, the basic requisites to the functioning of the mechanism of "pulling the production". Each selected requisite was confronted to the characteristics and peculiarities of the process and of the current technology of sugar manufacturing. We conclude that, in spite of the reported successes in the literature with the application of the JIT in continuous production systems, the Pull Production System does not turn out to be interesting or possible to the production of the sugar.
\end{abstract}

Key-words: pull production system; sugar manufacturing; pull production system in sugar manufacturing.

\title{
Referências
}


ABDULMALEK, F. A.; RAJGOPAL, J; NEEDY, K. L. A classification scheme for the process industry to guide the implementation of lean. Engineering Management Journal, v. 18, n.2, p.15-25, 2006.

ADVFN. Brasil - o maior produtor mundial de açúcar. Disponível em: <http://wiki.advfn.com/pt/Brasil__O_maior_produtor_mundial_de_a\%C3\%A7\%C3\%BAcar>. Acesso em: 02 set. 2010.

BILLESBACH, T. J. Applying lean production principles to a process facility. Production and Inventory Management Journal, Third quarter, p.40-44, 1990.

BRENNAN, D. Process industry economics. Warwickshire, UK: Institutions of Chemical Engineers, 2004.

COOK, R. L.; ROGOWSKI, R. A. Applying JIT principles to continuous process manufacturing supply chains. Production and Inventory Management Journal, Third quarter, p. 12-16, 1990.

COPERSUCAR. Cana-de-açúcar. Disponível em:

<http://www.copersucar.com.br/institucional/por/academia/cana_acucar.asp.>. Acesso em: 02 jun 2010.

CORRÊA, H. L.; CORRÊA, C. A. Administração da produção e operações: manufatura e serviços uma abordagem estratégica. São Paulo: Atlas, 2004.

EID, F.; PINTO, S. S.; CHAN, K. Mudanças tecnológicas na indústria sucroalcooleira: avanços e retrocessos. RECITEC - Revista de Ciência e Tecnologia, Recife, v.2, n.1, p.36-47, 1998.

GAITHER, N.; FRAZIER, G. Administração da produção e operações. São Paulo: Pioneira Thompson, 2001.

HAMERSKI, F. Estudo de variáveis no processo de carbonatação do caldo de cana-de-açúcar. Curitiba, 2009. 149p. Dissertação (Mestrado em Tecnologia de Alimentos). Setor de Tecnologia, Universidade Federal do Paraná (UFP).

HOPP, W. J.; SPEARMAN, M. L. Factory physics: foundations of manufacturing management. New York: McGraw-



KING, P. L. Lean for the process industries: dealing with complexity. New York: Taylor and Francis Group, 2009.

MAGALHÃES(a), A. C. M. Álcool e açúcar - unidade I - Extração e preparação. Disponível em:

<http://www.ebah.com.br/alcool-e-acucar-unidade-i-extracao-e-preparacao-doc-a17225.html>. Acesso em: 09 mar. 2010

MAGALHÃES(b), A. C. M. Álcool e açúcar - unidade II - Fabricação do açúcar. Disponível em: <http://www.ebah.com.br/alcool-e-acucar-unidade-ii-fabricacao-do-acucar-doc-a17226.html>. Acesso em: 09 mar. 2010

MAGALHÃES(c), A. C. M. Álcool e açúcar - unidade III - Cozimento. Disponível em: <http://www.ebah.com.br/alcool-e-acucar-unidade-iii-cozimento-doc-a17224.html>. Acesso em: 09 mar. 2010

MAGALHÃES(d), A. C. M. Álcool e açúcar - unidade IV - Centrifugação. Disponível em:

<http://www.ebah.com.br/alcool-e-acucar-unidade-iv-centrifugacao-doc-a17228.html>. Acesso em: 09 mar. 2010

MAGALHÃES(e), A. C. M. Álcool e açúcar - unidade V - Secadores. Disponível em:

<http://www.ebah.com.br/alcool-e-acucar-unidade-v-secadores-doc-a17229.html>. Acesso em: 09 mar. 2010

MAGALHÃES(f), A. C. M. Álcool e açúcar - unidade VI - Futuro - Disponível em: <http://www.ebah.com.br/alcoole-acucar-unidade-vi-futuro-doc-a17230.html>. Acesso em: 09 mar. 2010

MARAFANTE, L. J. Tecnologia da fabricação do açúcar e do álcool. São Paulo: Ícone, 1993.

MONDEN, Y. Toyota Production Systems: an integrated approach to Just-in-Time. Norcross, Georgia: Industrial Engineering and Management Press, 1998.

MONDEN, Y. Produção sem estoques: uma abordagem prática ao sistema de produção da Toyota. São Paulo: IMAM, 1984. 
MOULD, G; KING, M Just-in-time implementation in the Scottish electronics industry. Industrial Management and Data Systems, v.95, n.9, p.17-22, 1995.

MOURA, R. A. Kanban: a simplicidade do controle da produção. São Paulo: IMAM, 2000.

PAULINO, O. F. T. Produção de açúcar. Disponível em: <http://www.scribd.com/doc/13590596/Producao-deAcucar〉. Acesso em: 13 abr. 2010

PELERINI, F. L. Tecnologia da fabricação do açúcar e etanol a partir da cana de açúcar. Cândido Mota: Edição Independente, 2009.

ROTHER, M; SHOOK, J. Aprendendo a enxergar: mapeando o fluxo de valor para agregar valor e elimina desperdício. São Paulo: Lean Enterprise Institute, 2003.

SALAHELDIN, S. I. JIT implementation in Egyptian manufacturing firms: some empirical evidence. International Journal of Operations \& Production Management, v.25, n.4, p.354-370, 2005,

SHIN, D.; MIN, H. Flexible line balancing practices in a just-in-time environment. Production and Inventory Management Journal, v.32, n.4, p.38-41, 1991.

SHINGO, S. O sistema Toyota de produção. $2^{\text {a }}$ Ed. Porto Alegre: Bookman, 1996.

SPEARMAN, M. L; ZAZANIS, M. A. Push and Pull Production Systems: Issues and Comparisons. Operations Research, v.40, n.3, p. 521-532, 1992.

SWANSON, C. A.; LANKFORD, W. M. Just-in-time manufacturing. Business Process Management Journal, v.4, n.4, pp. 333-341, 1998.

TUBINO, D. F. Manual de planejamento e controle da produção. São Paulo: Atlas, 2000.

Sistemas de produção: a produtividade no chão de fábrica. Porto Alegre: Bookman, 1999.

TUBINO, D. F.; ANDRADE, G. J. P. A implantação de sistemas puxados de programação da produção em ambientes de demandas instáveis. In. XXIII Encontro Nacional de Engenharia de Produção - Ouro Preto, MG. Anais... Ouro Preto: ABEPRO, p. 1-9, 2003.

WAFA, M. A.; YASIN, M. M. A conceptual framework for effective implementation of JIT: an empirical investigation. International Journal of Operations \& Production Management, v.18, n.11/12, p.1111-1124, 1998.

YASIN, M. M.; WAFA, M. A.; SMALL, M, H. Just-in-time implementation in the public sector: an empirical examination. International Journal of Operations \& Production Management, v.21, n.9, p.1195-1204, 2001.

Nome completo: Marcelo Giroto Rebelato

Filiação institucional: FCAV - UNESP - Jaboticabal

Departamento: Economia Rural

Função ou cargo ocupado: Professor

Endereço completo para correspondência (bairro, cidade, estado, país e CEP): Via de Acesso Prof.

Donato Castellane s/n - 14884-900 - Jaboticabal - SP

Telefones para contato: 16 3209-2635

e-mail:magiroto@yahoo.com.br

Nome completo: Leonardo Lucas Madaleno

Filiação institucional: Centro Paula Souza - FATEC/Jaboticabal 
Departamento: não há

Função ou cargo ocupado: Professor

Endereço completo para correspondência (bairro, cidade, estado, país e CEP): Via de Acesso Prof.

Donato Castellane s/n - 14884-900 - Jaboticabal - SP Telefones para contato: 1632026519

e-mail:leoagro@gmail.com

Nome completo: Andréia Marize Rodrigues

Filiação institucional: FCAV - UNESP - Jaboticabal

Departamento: Economia Rural

Função ou cargo ocupado: Professora

Endereço completo para correspondência (bairro, cidade, estado, país e CEP): Via de Acesso Prof.

Donato Castellane s/n - 14884-900 - Jaboticabal - SP

Telefones para contato: 16 3209-2635

e-mail: rodriguesmarize@terra.com.br

Enviado em: 23/09/2010

Aprovado em: 09/03/2011 